\title{
AUTOMATED TELLER MACHINE-BASED VOTING SYSTEM
}

\section{Ayokunle A. Omotunde ${ }^{1}$, Martin Ejenobor ${ }^{2}$, Ernest E. Onuiri ${ }^{3}$, Izang Aaron ${ }^{4}$,}

\section{Ajayi Wumi ${ }^{5}$ and Adekola Olubukola ${ }^{5}$}

${ }^{1}$ Department of Information Technology, Babcock University, Ilishan Remo, Ogun State, Nigeria. Email: ayo_omotunde@yahoo.com

${ }^{2}$ Development Services, Revele Consulting, Lagos State, Nigeria

${ }^{3}$ Computer Science Department, Babcock University, Ilishan Remo, Ogun State, Nigeria

${ }^{4}$ Department of Information Technology, Babcock University, Ilishan Remo, Ogun State, Nigeria

${ }^{5}$ Department of Software Engineering, Babcock University, Ilishan Remo, Ogun State, Nigeria

Cite this article:

Ayokunle A.O., Martin E. Ernest E.O., Izang A., Ajayi W., Adekola O. (2021), Automated Teller MachineBased Voting System. British Journal of Computer, Networking and Information Technology 4(2), 31-41. DOI: 10.52589/BJCNITBPP3LY55.

\section{Manuscript History}

Received: 29 Aug 2021

Accepted: 17 Sept 2021

Published: 22 Sept 2021

Copyright $\odot 2020$ The Author(s). This is an Open Access article distributed under the terms of

Creative Commons Attribution-

NonCommercial-NoDerivatives 4.0 International (CC BY-NC-ND

4.0), which permits anyone to

share, use, reproduce and

redistribute in any medium,

provided the original author and source are credited.
ABSTRACT: Voting is a critical element of any election which involves the processes of electing leaders or representatives into positions of authority in a democratic system of government. In most developing countries of the world, this process is usually marred with challenges of confidentiality, integrity, availability and auditability such as falsification of results, identity theft, theft of ballot boxes, multiple voting problems, over voting, and electoral fraud. This paper presents a framework for Automated Teller Machine-based voting system that solves the aforementioned challenges of the current voting system by using the existing Automated Teller Machines and debit cards issued for voting. Going further to implement the solution proposed in this paper will enhance and guarantee the credibility of the electoral processes and show a true reflection of the wishes of the people.

KEYWORDS: e-Voting, Automated Teller Machine, Bank Verification Number, National Identity Number. 


\section{INTRODUCTION}

Over the years, nations governed by democracy have taken giant strides toward strengthening democratic processes, which ensure that each citizen has the right to make their own decisions, especially when it comes to exercising their freedom in electing leaders who represent them in government. However, in Nigeria, a lot of people are of the opinion that the electioneering processes are fraught with vices such as imposition of candidates, vote rigging, voter intimidation, vote buying, ballot snatching, ballot box stuffing and manipulation of results. This opinion is substantiated by the reports from Transition Monitoring Group (TMG), the Carter Center, National Democratic Institute (NDI), International Republican Institute (IRI) and the European Union Election Observer Mission (EU-EOM) during the 2003, 2007 and 2011 general elections respectively. Furthermore, the will of the voters have not been adequately captured since 1999 [1], [2], [3], [4], [5], [6], and the declining quality of general elections in Nigeria is a threat to democratic consolidation [7].

\section{REVIEW OF LITERATURE}

\section{Review of Electronic Voting (E-voting) systems}

e-Voting systems were initially developed as a panacea for the problems inherent in the paperbased voting system. Several solutions have been proposed, and these solutions are examined in this section. A historical trend of voting systems in Nigeria was highlighted by [8] after which a secured voting system that was not prone to manipulation, rigging and complaints from citizens and political parties was designed. However, it was able to achieve only authentication but was not able to achieve confidentiality, integrity, transparency, convenience and auditability of functional and security requirements; hence, it was impracticable to use. [9] provided a solution to the security issues of online voting systems with user biometric and password features for authentication. It was achieved by using the voter's fingerprint and password to achieve authentication while the least significant bit (LSB) was used to hide the results and Message-Digest algorithm 5 to achieve integrity. The research achieved the authentication and confidentiality requirement of e-voting systems but could not solve the problem of convenience and auditability.

In order to solve the problem of time wastage when it comes to counting ballot paper and wastage of resources and manpower, [10] proposed an advanced microcontroller-based biometric authentication voting machine. The downside of this work was that it also could not achieve confidentiality, integrity, secrecy, transparency, convenience and auditability of evoting functional and security requirements.

Due to the problems of impersonation that eventually lead to false results, [11] developed a secure e-voting system where a KY-M 16 fingerprint sensor was used to capture the voter's fingerprints and WINCE 6 environment was leveraged on to interface the ARM processor. Formulation of a fingerprint pattern technique to achieve authentication in fulfilling the security requirements of the electronic voting system was achieved. However, the solution failed to achieve confidentiality, integrity, transparency and convenience and audibility. [12] also addressed the problem of rigging and impersonation with another biometric fingerprint solution using the FIM $3030 \mathrm{~N}$ scanner for extracting, processing and storing the ridges of the prints in a database. The work was able to achieve a reasonable level of authentication; 
however, it also failed in the areas of confidentiality, integrity, convenience and auditability. To prevent impersonation in a situation of a stolen voter's ID card, [13] proposed an iris recognition-based voting system where voters' iris patterns are matched with pre-deposited images in the database. This work was also very good at achieving authentication but failed on the confidentiality, integrity, convenience and auditability front.

An Internet-of-Things-based solution was proposed by [14] to curb the problem of impersonation and delay in result announcement resulting from slow process of collation. The ridge and valley features extraction techniques were used for authentication and the election data was transferred to the main database. A ridge extraction technique was presented and used to achieve authentication as a measure towards the attainment of e-voting requirements. The challenges of confidentiality, integrity, secrecy, transparency, convenience and auditability of e-voting functional and security requirements were not tackled. Another solution to impersonation and falsification of election results was proposed by [15] with the design, development and evaluation of a secure electronic voting system using fingerprint and cryptowatermarking approach. This system worked by leveraging fingerprint biometrics, Advanced Encryption Standard and wavelet watermarking techniques. As voters registered their fingerprints, personal identification numbers were serially allotted for the purpose of authentication. The voting system could be accessed via a PC and it addressed the issue of authentication, integrity and confidentiality. The problems of secrecy, transparency, convenience and auditability of e-voting functional and security requirements were not handled.

A smart voting machine was developed by [16] for the purpose of addressing the problem of manual checking of voters' details for identification, ineffective voting procedure and counting. A unique key and fingerprint biometrics were used for authentication and results were transmitted to the mobile phone of the election commissioner. The fingerprint biometrics and unique key were used to achieve verification. The problems of confidentiality, integrity, secrecy, transparency, convenience and auditability of e-voting functional and security requirements were not addressed as the results communicated through the unprotected network could be intercepted by imposters.

Another IoT based solution was developed by [17] to solve the same problem of impersonation as a result of the paper-based technique of voters' identification with the use of the PIC16F874A/877A microcontroller, fingerprint scanner, ZigBee (CC2500), Liquid Crystal Display (LCD), buzzer and power supply. The major setback of this work is the challenges of confidentiality, integrity, convenience and auditability of the functional and security requirements.

This review of literature corroborates the extensive review done by [18] and it is clear that there are fundamental issues with e-voting systems that range from impersonation to authentication, to confidentiality, to integrity, to convenience and to auditability. While some of the systems proposed by [16], [15], [13] solved the problem of authentication, the issue of confidentiality, integrity, convenience and auditability were not addressed. 


\section{Overview of voting system in Nigeria}

Election is seen as the most essential ingredient of democracy and as such it is fundamental to the survival, steadiness and progress of any democratic country - [19], [20]. In Nigeria, the body charged with the responsibility of conducting and supervising elections is the Independent National Electoral Commission (INEC). So far, four methods have been used for voting in Nigeria. These are Open Ballot System (OBS), Modified Open Ballot System (MOBS), Remodified Open-secret Ballot System (REMOBS) and Continuous Accreditation and Voting System (CAVS) - [21]. The OBS is that in which the voters elect their candidates openly. This contrasts with the secret ballot that conceals the vote options from others. The MBOS amends the OBS by allowing voters to cast their votes secretly. This method was adopted in the 1999, 2003, and 2007 general elections in Nigeria. The REMOBS is an advanced form of the MOBS where accreditation is done before ballot papers are released to voters, and then they can go and elect their candidates in private. With CAVS, accreditation and voting are done concurrently. The accreditation process comprises verification by the SCR, checking of the register of voters and inking of the cuticle of the specific finger. After accreditation, the voter is issued ballot papers to make his choice secretly inside the cubicle before depositing the ballot papers inside the box in the presence of everyone in the polling station. The OBS, MOBS, and REMOBS were used before the introduction of PVC while the CAVS was implemented with the introduction of PVC.

\section{Pre-Permanent Voters Card (PVC) Era}

For many years in the world, the paper-based voting system has been used as a method of casting votes during an election exercise. Nigeria is not exempted from the paradigm of voting and thus inherits the stressful and, in most cases, untrustworthy nature of this process. In a country like Nigeria where the population is rather high, it may take days to conduct an election and announce the final results.

\section{Challenges}

It is common knowledge that the paper-based voting system gave room for modification of the election result. This is because the system allows a voter to register and vote more than once, resulting in unwanted candidates emerging as winners. What makes voters doubt the integrity of the election system more is the fact that the results of the elections are not being verified by voters and are being scanned and transmitted through an unprotected network - [18].

\section{Permanent Voters Card (PVC) Era}

Electoral malpractice is antithetical to the development of Nigeria. Although a lot of efforts have been made at different levels to address the ugly scenario, the battle is not yet won. In 2015, INEC introduced the Permanent Voters Card (PVC) card reader for accreditation. The following explicates the procedure for voting at the polling unit, according to [21]. At the polling unit, an INEC official checks whether one is at the correct polling unit; then, the genuineness of the PVC is checked by using the card reader. Once the voter has been accredited, his name is ticked on the list and his finger is inked to confirm that he has voted. A ballot paper is stamped and signed by the presiding officer and the voter directed to a voting cubicle. After selecting a preferred candidate, he then leaves the voting cubicle and drops the ballot paper in the ballot box in the presence of the people at the polling unit. 


\section{Challenges with using the PVC}

1) Rigging which leads to the lack of integrity.

2) Lack of confidentiality since the open ballot system is in use.

3) In some situations, the ballot papers and boxes are not available at polling units either due to security reasons or for the sheer intention of ballot box stuffing.

4) Voters must stand in a long queue before they can have the opportunity to cast their votes. This experience is rather inconvenient for many and has pushed some to the point where they have chosen not to vote anymore.

5) Because of the current system being run, the entire process is not auditable. This shortcoming has given many officials the audacity to engage in unlawful acts.

\section{ANALYSIS AND DESIGN}

In order to tackle the issue of unavailability of presiding officers, confidentiality, integrity of voters and their choices, convenience and auditability of the voting system, this paper proposes an ATM based solution for voting.

\section{Reasons for ATM}

1) ATM is linked to a bank account that has a composite key generated from:

a) Bank Verification Number also known as BVN

b) National Identity Number-NIN, and

c) Bank Account Number.

All stated (a-c) above are for identifying each person. However, the more important attributes are the BVN and NIN. The BVN is a Biometric Identification System that was implemented by the Central Bank of Nigeria to curb illegal banking. The NIN is a set of numbers assigned to an individual upon enrolment. The enrolment consists of the recording of an individual's demographic data, fingerprints, head-to-shoulder facial picture and digital signatures, which are all used to cross-check existing data in the national identity database to confirm that there is no previous entry of the same data. With these attributes, integrity is ensured. Personal verification information such as PIN is used. This also ensures integrity.

2) Transactions made on ATMs (deposits, transfers, etc.) are reliable and are kept confidential since they are connected to the central server over protected networks.

3) The technique used to ensure that there is a transaction log for every transaction carried out using a credit/debit card and a log of activities on the ATM will also suffice in providing integrity and auditability. 


\section{Process flow of the proposed solution}

e-Voting as proposed in this paper is divided into five processes which consist of registration, verification, casting, counting/collation, and presentation of results. The main system flow chart is presented in figure 1. It is assumed that this system is only usable by registered citizens.

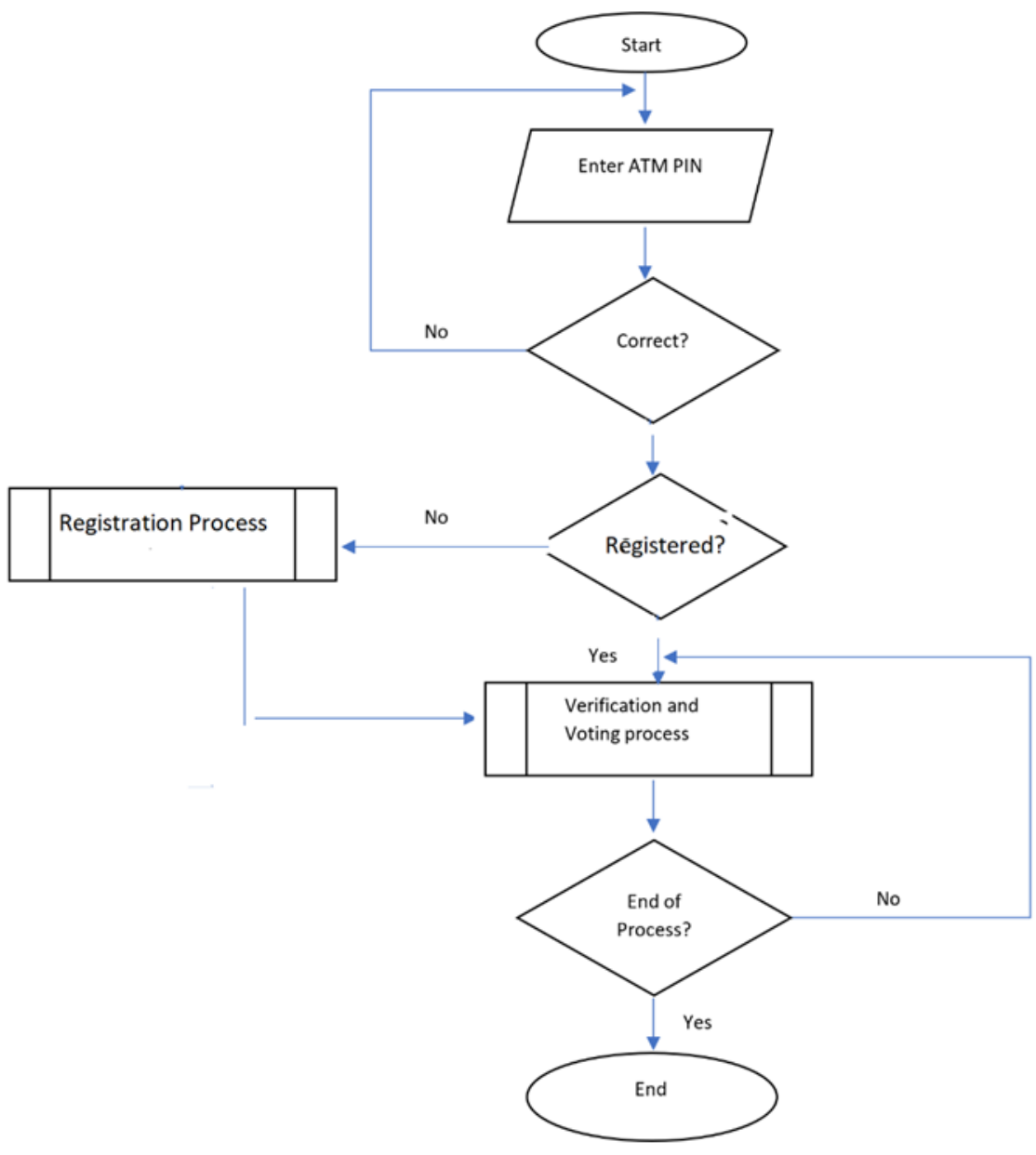

Figure 1: Flow chart for the proposed system

\section{Registration}

The details captured upon registration of BVN and NIN can serve as the details for the voting registration process since the details captured with these two can suffice as there are enough parameters to capture basic voters' details. Figure 2 presents the Use Case diagram for BVN registration while figure 3 presents the procedure for NIN registration. 


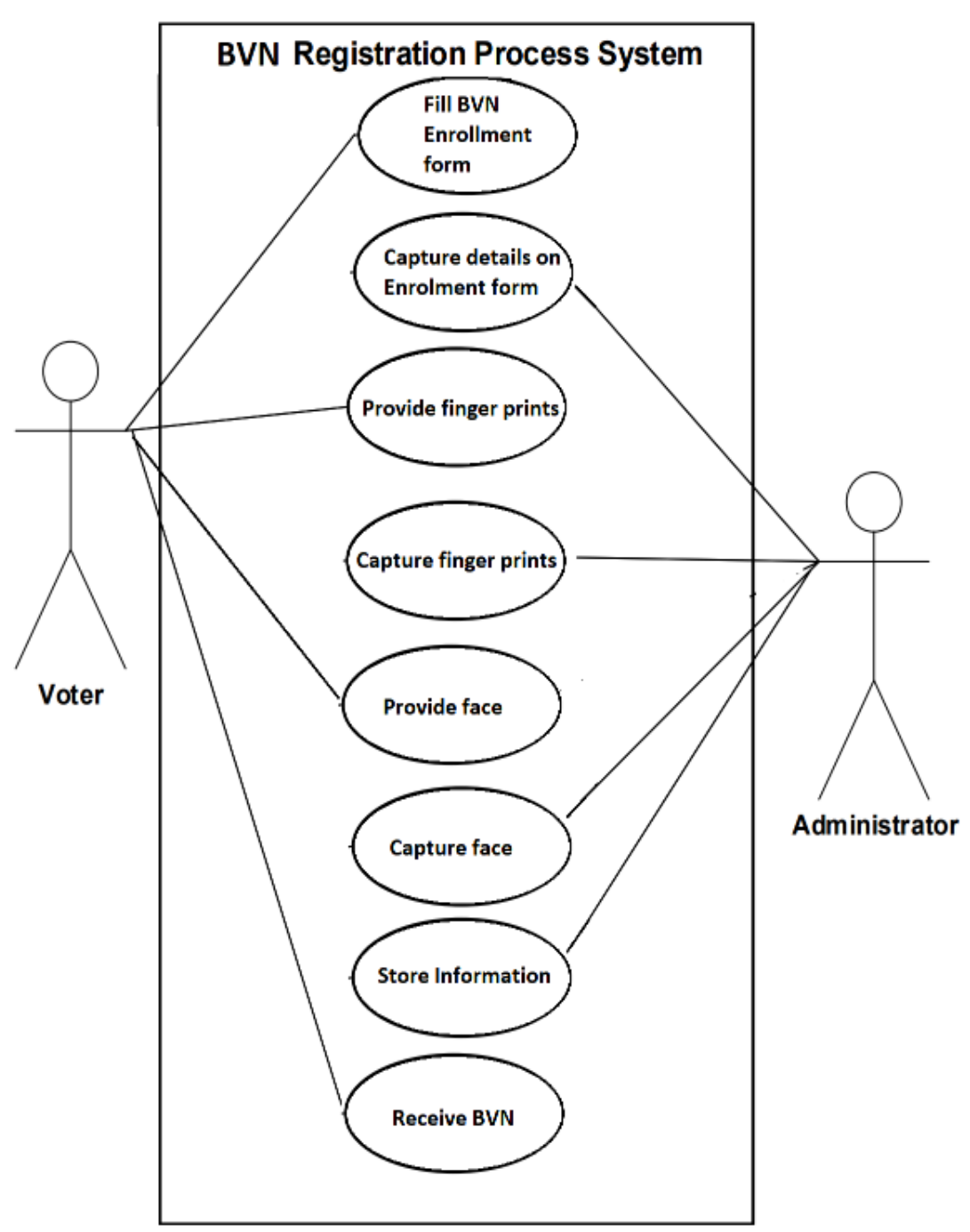

Figure 2: Use Case diagram of BVN registration process. 
British Journal of Computer, Networking and Information Technology

ISSN: $2689-5315$

Volume 4, Issue 2, 2021 (pp. 31-41)

www.abjournals.org

$$
\begin{aligned}
& \text { Applicant walks in to an Step } 1 \\
& \text { Enrolment Centre with } \\
& \text { supporting documents and is } \\
& \text { verified not have previously } \\
& \text { enrolled. }
\end{aligned}
$$

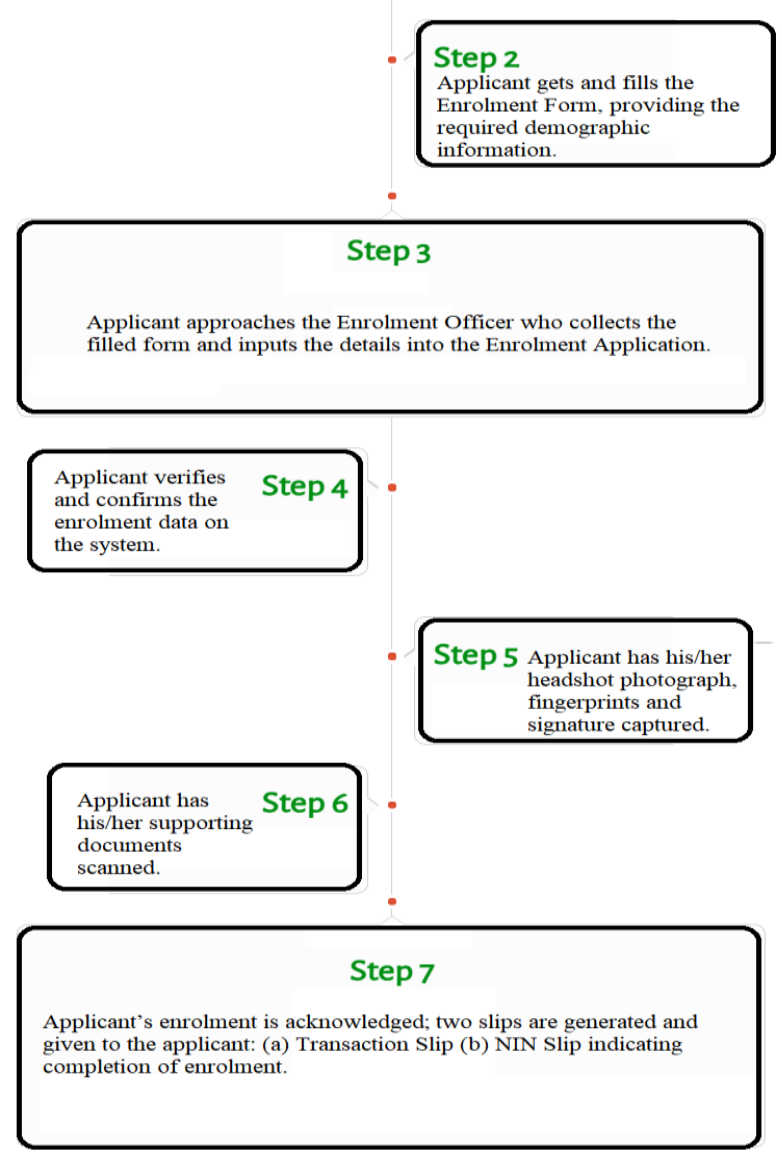

Figure 3: Procedure for NIN Registration

\section{Verification and Voting casting}

With cameras and fingerprint scanners on ATMs, verification can be done to ascertain whether the card holder is the card owner and casting of vote is done immediately after the verification process. The vote casting phase involves downloading ballot forms, selecting candidates and submitting votes. The flowchart is depicted in figure 4 . 


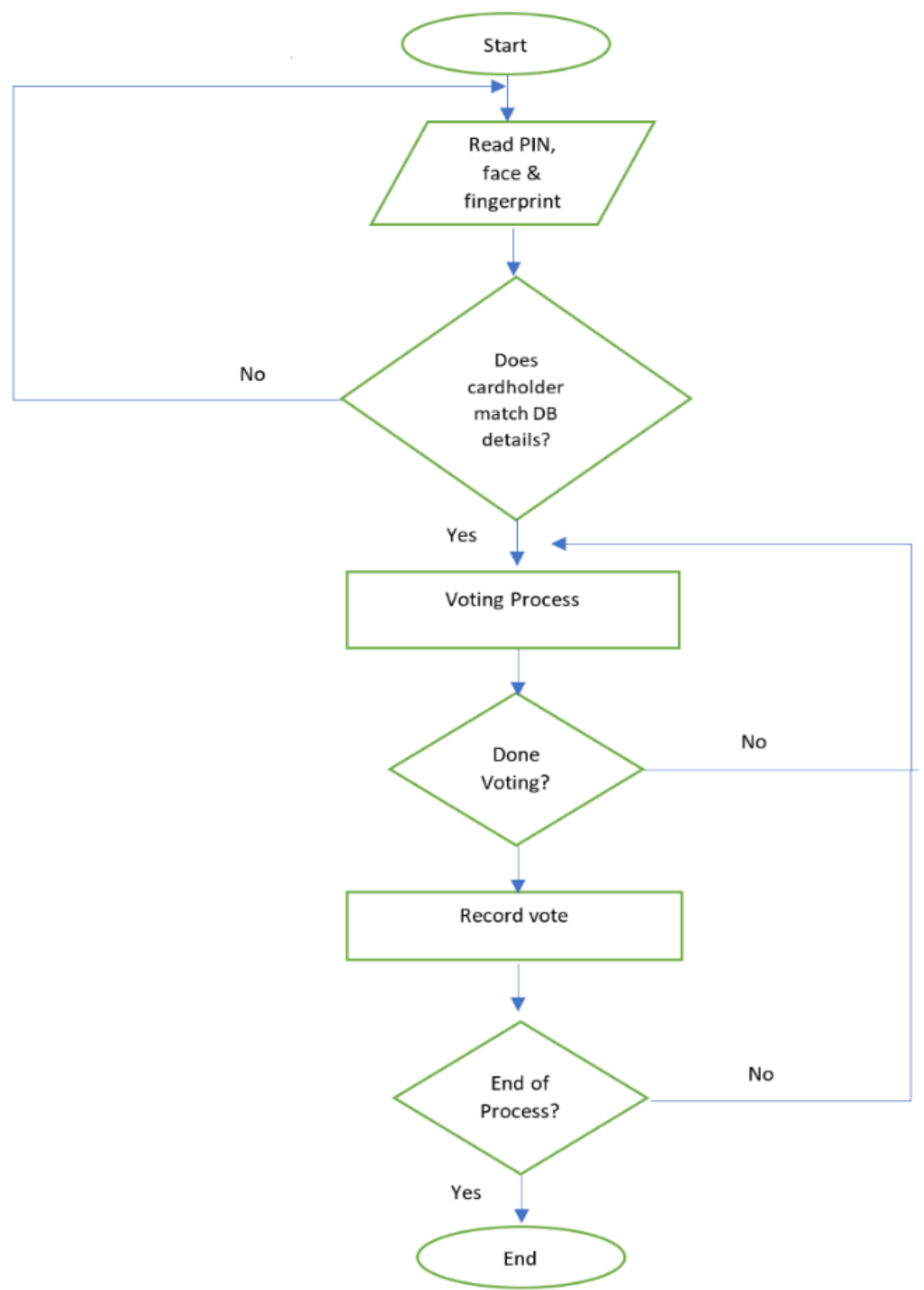

Figure 4: Verification and voting process in the proposed framework

\section{Collation/Counting}

As votes are recorded in the verification/vote casting phase, the database is being updated and the collation is being done.

\section{Presentation of results}

Once the election process is concluded, the results can then be sent to voters in the same way monthly bank statements are sent to customers. 


\section{CONCLUSION}

Voting is an essential part of democracy; however, it is fraught with many vices and irregularities such as ballot box stuffing, vote rigging, and vote intimidation. These have ultimately affected the outcome of the election exercise. The proposed solution is to use existing ATM machines to curb the aforementioned vices based on the following premises: the banks already have attributes that uniquely identify every citizen, thus ensuring integrity and auditability of the election process, and confidentiality is ensured since all the ATM terminals can be connected to a central repository.

In order to fully harness the advantages of the proposed system, the following recommendations are being made:

1. The level of literacy among citizens concerning the need to get their Bank Verification Number and National Identity Number should be improved as this forms the basis upon which the ATM based voting system will run.

2. A high level of security should be maintained by electoral bodies in order for voters to have more confidence and independence of the system.

3. Further study can be carried out towards implementing the solution proposed in the paper.

\section{REFERENCES}

[1] Aluaigba, TM 2009a, 'The travails of an emerging democracy: the turbulent 2007 general elections in Nigeria', Mambayya House Journal of Democratic Studies, vol. 1, no. 1, pp. 23-38.

[2] Bratton, M 2008, 'Vote buying and violence in Nigerian election campaigns', Afro Barometer Working Paper no. 99, viewed 27 October 2012,

[3] Ezeani, EO 2005, 'Electoral malpractices in Nigeria', in G Onu \& A Momoh (eds), Elections and democratic consolidation Nigeria, Nigerian Political Science Association, Lagos.

[4] Oddih, M 2007, 'Electoral fraud and democratization process: lessons from the 2003 elections', in MA Jega \& O Ibeanu (eds), Elections and the future of democracy in Nigeria, Nigerian Political Science Association, Lagos.

[5] Ojo, OE 2008, 'Vote buying in Nigeria', in VAO Adetula (ed), Money and politics in Nigeria, International Foundation for Electoral System, Abuja.

[6] Suberu, TR 2007, 'Nigeria's muddled elections', Journal of Democracy, vol. 18, no. 4, October, pp. 95-110.

[7] Nwangwu, C., Onah, V. C., \& Otu, A. O. (2018). Elixir of Electoral Fraud: The Impact of Digital Technology on the 2015 General Elections in Nigeria. Cogent Social Sciences, 4(1). doi:10.1080/23311886.2018.1549007

[8] Ajayi, L. B. (2004). A Secure Electronic Voting System. Federal University of Technology, Department of Computer Science. Akure: Unpublished.

[9] Neha, G. (2014). "Study on security of online voting system using biometrics and stenography. International Journal of Computer Science and Communications, 5(1), 2932. 
[10] Farhath, B. A., Deepa, M., \& Kalaivani, C. N. (2014). Advanced microcontroller based Biometric authentication voting machine. International Organization of Scientific Research Journal of Engineering, 4(5), 29-40.

[11] Sudhakar, M., \& Divya, B. S. (2015). Biometric System-based Electronic Voting Machine using ARM9 Microcontroller. Journal of Electronics and Communication Engineering, 10(1), 57 -65.

[12] Panja, S., \& Mondeddu, S. (2015). Biometric Finger print based Electronic voting system for rigging free governance. International Journal and Magazine of Engineering, Technology, Management and Research,, 2(12), 526-529.

[13] Nithya, M. J., Abinaya, G., B., S., \& Saravana, M. L. (2015). Iris Recognition System. International Conference on Science, Technology, Engineering and Maangement, 10, 44-51.

[14] Nithya, S., Ashwin, C., Karthikeyan, C., \& Ajith, K. M. (2016). Advanced secure voting system with IoT. International Journal of Engineering and Computer Science, 5(3), 16033 - 16037.

[15] Olayemi, M. O., Taliha, A. F., Aliyu, A., \& Olugbenga, J. (2016). Design of secure electronic voting system using fingerprint biometrics and crypto-watermarking approach. International Journal of Information Engineering and Electronic Business (IJIEEB), 8(5), 9-17. doi:DOI: 10.5815/ijieeb.2016.05.02.

[16] Trupti, S. T., Palak, S., Rashmi, D. P., Samit, K., \& Saurabh, K. (2017). Smart Voting Machine. International Journal of Science Technology and Engineering, 3(12), 143-147.

[17] Snega, S., Saundarya, S., \& Balraj, R. (2018). Highly secured electronic coting machine using aadhaar in IOT platform. International Journal of Electrical and Electronics Research, 6(2), 41-47.

[18] Adewale, O., Boyinbode, O., \& Salako, A. (2020). A Review of Electronic Voting Systems: Strategy for a Novel. International Journal of Information Engineering and Electronic Business, 1, 19-29. doi:10.5815/ijieeb.2020.01.03

[19] Okoli, A. C., \& Iortyer, P. (2014). Electioneering and Dialectics of Political Stability in Nigeria: Implications for Sustainable Democracy. Research on Humanities and Social Sciences, 4(13).

[20] Yusuf, I., \& Zaheruddin, O. (2015). Challenges of Electoral Processes in Nigeria's Quest for Democratic Governance in the Fourth Republic. Research on Humanities and Social Sciences, 5(2).

[21] Esan, A. O., \& Ayeni, P. T. (2018). E-Voting in Nigeria: Barriers to Full Implementation. Journal of Computer Engineering and Information Technology, 7(1). doi:10.4172/2324-9307.1000203

[22] INEC. (2021, March 13). How to vote. Retrieved from https://www.inecnigeria.org/: https://www.inecnigeria.org/voter-education/how-to-vote/ 